\title{
Possible prevention and treatment of steroid-induced osteoporosis
}

\author{
*JOHN R. CONDON \\ B.Sc., M.B., M.R.C.P. \\ $\S$ C. E. DENT + \\ D.Sc., M.D., F.R.C.P.
}

\author{
$\dagger$ J. R. NASSIM $\ddagger$ \\ F.R.C.P. \\ TANN HiLb
}

ףE. M. STAINTHORPE
B.Sc.

\begin{abstract}
* Metabolic Unit, Brook General Hospital, London; † St George's Hospital and Royal National Orthopaedic Hospital, London; § Department of Metabolism, University College Hospital, London and If Royal National Orthopaedic Hospital, London
\end{abstract}

\begin{abstract}
Summary
Patients with steroid-induced, juvenile and senile osteoporosis were studied using balance techniques.

The changes in calcium and phosphorus balance associated with glucocorticoid therapy were corrected with vitamin $D$ and bendrofluazide given in combination. No hypercalcaemia occurred in osteoporotic patients who continued to receive glucocorticoids. Calcium and phosphorus balance was also improved in the osteoporotic subjects not receiving steroids, but these patients became hypercalcaemic during treatment.

It is suggested that vitamin $D$, bendrofluazide and steroids antagonize the actions of one another on the renal tubule, gut and bone and in this way prevent the increased calciuria which occurs with glucocorticoid therapy. Since the increased calciuria and negative calcium balance induced by glucocorticoids is considered to be the result of excessive bone resorption, an adequate dose of bendrofluazide and vitamin $D$ in combination might prevent the development of, or even reverse, steroid-induced osteoporosis.
\end{abstract}

\section{Introduction}

Theoretically, osteoporosis may represent an imbalance of factors which affect the formation and resorption of bone (Pak and Bartter, 1972). In man, glucocorticoid-induced osteoporosis is usually considered to be the result of increased bone resorption (Jowsey et al., 1965; Gallagher et al., 1973; Wajchenberg et al., 1969), although decreased bone formation may also contribute to some extent (Riggs, Jowsey and Kelly, 1966).

$A$ rise in urinary calcium and a negative calcium balance usually develops in patients given large doses of glucocorticoids, and since these drugs inhibit intestinal absorption of calcium in animals

$\ddagger$ Deceased. and man (Stoerk and Arison, 1961; Collins, Garrett and Johnston, 1962; Bunim et al., 1958; Slater et al., 1959; Nordin et al., 1968; Gallagher et al., 1973) the increased urinary calcium is generally considered to be the result of excessive bone resorption.

It would, therefore, be reasonable to assume that if the increased calciuria and negative calcium balance induced by glucocorticoids were reversed, the development of osteoporosis might be prevented or modified.

The authors have been able to correct the changes in calcium and phosphorus balance associated with glucocorticoid therapy, by the use of a simple regime which was also given to two osteoporotic patients who were not receiving glucocorticoids. Calcium and phosphorus balance studies are reported in these five individuals. The possibility that the drugs used may be of therapeutic benefit in glucocorticoid-induced and possible other forms of osteoporosis is discussed.

\section{Methods}

Balance study techniques and phosphate analysis have been previously reported (Walker and Collins, 1965). Balance periods were 6 days in patients 1,2 , and 3; and 4 days in patients 4 and 5 . Carmine dye was used as a period marker. Faecal calcium and phosphorus values were corrected for barium sulphate or copper thiocyanate, one of which was used as a continuous faecal marker. Faecal barium was estimated by atomic absorption spectrophotometry and faecal copper by the method of Dick (1969).

Urinary inorganic phosphate was estimated on all urine samples using the autoanalyser method N4b (Technicon Autoanalyser Handbook). Calcium analysis was performed by atomic absorption spectrophotometry on the Unicam SP 96 model using Unicam atomic absorption method $\mathrm{Ca} 2$. 


\section{Results}

Balance studies are represented graphically in Fig. 1.

\section{Case 1}

A 36-year-old man with rheumatoid arthritis who developed hypercalciuria and a negative calcium balance when given prednisolone $20 \mathrm{mg}$ daily. Calciferol $0.5 \mathrm{mg} /$ day and bendrofluazide $5 \mathrm{mg} /$ day was given and the patient taken off balance. The patient was 'rebalanced' eighteen days later. Hypercalciuria had been controlled and a positive calcium balance induced by therapy. There was no rise in plasma calcium which remained between 8.9 and $9 \cdot 6 \mathrm{mg} / 100 \mathrm{ml}$ during therapy.
Case 2

A man who had been treated for severe asthma with prednisolone $20-30 \mathrm{mg} /$ day for 6 years. The patient had lost 2 inches in height and had severe back pain. Radiological examination of the spine revealed osteoporosis with collapse of L3 L4 vertebrae. Balance studies showed the patient to be in negative calcium balance and when given $1 \mathrm{mg}$ of calciferol daily urine calcium increased and faecal calcium fell. Calcium balance remained virtually unaltered until bendrofluazide $5 \mathrm{mg}$ daily was added $\vec{\circ}$ to the regime. This caused a fall in urine calcium and calcium balance became zero. When the bendrofluazide was started, the dose of calciferol was reduced to $0.5 \mathrm{mg}$ daily. This reduction in vitamin $\mathrm{D}$

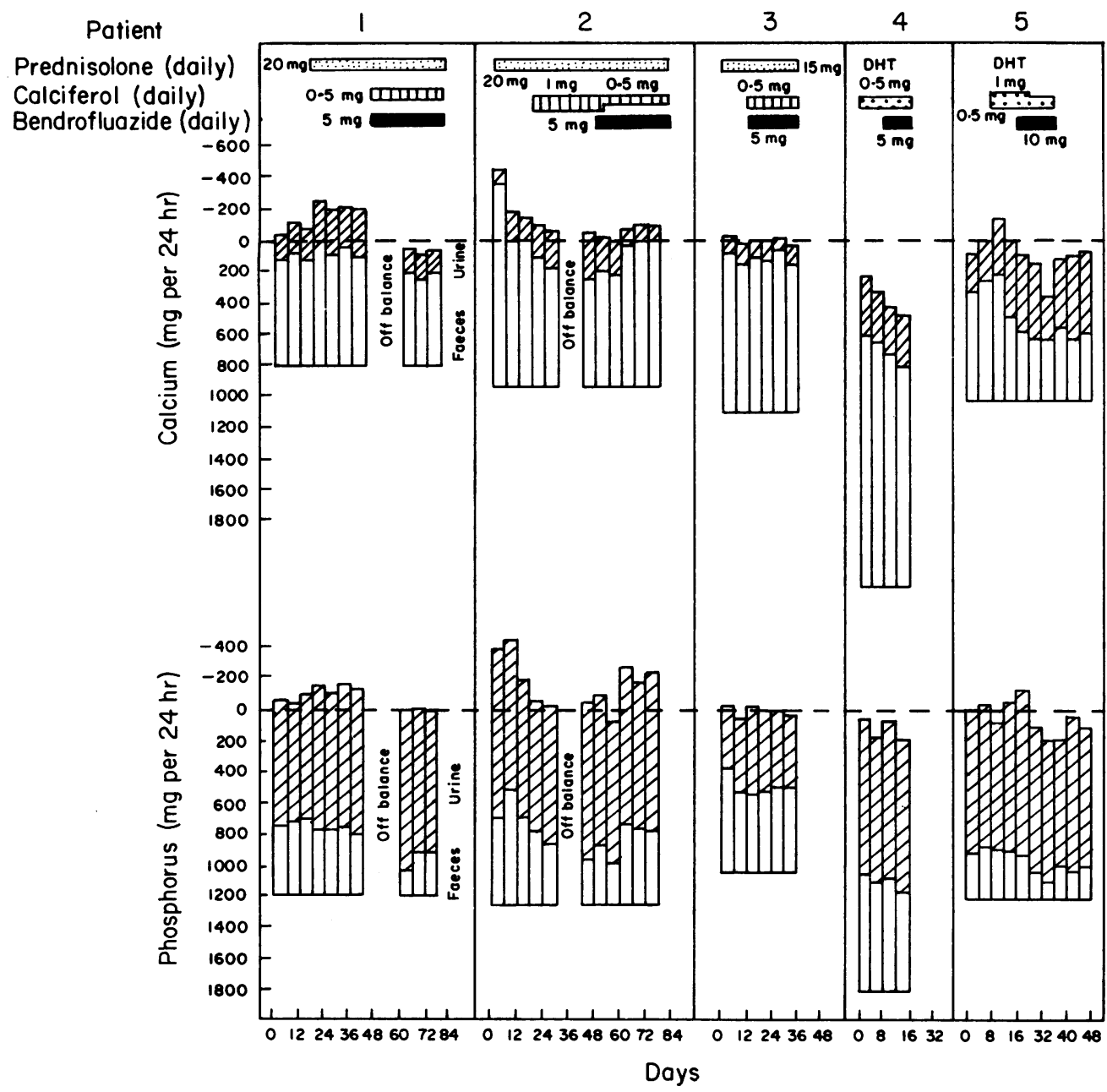

FIG. 1. Calcium and phosphorus balance studies in patients given prednisolone (patients 1-3) and not given prednisolone (patients 4-5) treated with bendrofluazide and vitamin D. DHT = dihydrotachysterol. 
dosage caused a further rise in faecal calcium and the development of a negative calcium and phosphorus balance. Urine calcium remained well within normal limits.

Treatment was continued with $0.75 \mathrm{mg}$ of calciferol and $5 \mathrm{mg}$ of bendrofluazide in addition to prednisolone. There was relief of back pain within 6 months and there was no further loss of height over 18 months. The calcium balances were not repeated during this period of time.

\section{Case 3}

A 62-year-old woman with rheumatoid arthritis had been treated with prednisolone 7-15 $\mathrm{mg}$ /day for 8 years. On admission for balance studies the patient was receiving $7.5 \mathrm{mg} /$ day of prednisolone and this was increased to $15 \mathrm{mg} / \mathrm{day}$. The patient was balanced and at the beginning of the third period calciferol and bendrofluazide were begun. There was no significant change in her calcium balance or urine and faecal calcium over the next 24 days. It is realized, in retrospect, that longer balances with a higher dosage of vitamin $\mathrm{D}$ were necessary to induce a positive calcium balance.

\section{Case 4}

An 11-year-old male with juvenile osteoporosis, whose calcium balance improved markedly to $+440 \mathrm{mg}$ with dihydrotachysterol (DHT) and bendrofluazide. Hypercalcaemia developed after 16 days of treatment which was discontinued.

\section{Case 5}

A 68-year-old man with senile osteoporosis. Treatment with $1 \mathrm{mg} /$ day of DHT and bendrofluazide resulted in a marked improvement of calcium balance. Treatment was discontinued because hypercalcaemia developed, despite the reduction of DHT to $0.5 \mathrm{mg} /$ day.

\section{Discussion}

Hypercalciuria and a negative calcium balance invariably develop in patients given very large doses of glucocorticoids. This effect is probably dosedependent (Pechet, Bowers and Bartter, 1959; Geschwind, 1961; Eisenberg, 1966; Wajchenberg et al., 1969) and due to defective intestinal and renal tubular resorption of calcium (Pechet et al., 1959; Gallagher et al., 1973).

The authors have improved calcium balance by using a combination of drugs the individual actions of which are well known. Vitamin D increases intestinal absorption of calcium and faecal calcium falls. The compound would thus be expected to correct the intestinal defect of calcium absorption due to glucocorticoids and this appears to be the case (Nordin, 1973). Although administration of vitamin D and of glucocorticoids results in increased calciuria, it does so by different mechanisms. Large doses of glucocorticoids raise urinary calcium by inhibiting renal tubular resorption of the ion (Pechet et al., 1959) whereas, in the presence of normal parathyroid glands, vitamin $\mathbf{D}$ probably increases renal tubular resorption of calcium (Gran, 1960; Nordin, 1973) causing an increase in plasma calcium with resultant hypercalciuria. Vitamin D and glucocorticoids, therefore, have opposite actions on the renal tubule and would be expected to counteract each other.

Both glucocorticoids (Jowsey et al., 1965; Gallagher et al., 1973) and vitamin D increase bone resorption. In the case of glucocorticoids there are two possible mechanisms by which this may occur; it may be secondary to a prolonged negative calcium balance caused by the action of glucocorticoids on the gut and renal tubule and in support of this osteoporosis can be induced in animals by a calcium deficient diet (Crawford et al., 1957; Harrison and Frazer, 1969; Jawsey and Gershon-Cohen, 1964). On the other hand, increased bone resorption may be due to a direct action of glucocorticoids on bone. There is in fact evidence which points to the reverse; namely, that glucocorticoids actually inhibit bone resorption (Raisz et al., 1972; Nisbet and Nordin, 1969). Indeed, although the exact mechanism of action is unclear, many patients with malignant hypercalcaemia and vitamin D overdosage (Myers, 1962; Verner, Engel and McPherson, 1958), two disorders in which bone resorption may be high, respond to glucocorticoid therapy by normalization of serum calcium.

Thus, the negative calcium balance induced by large doses of glucocorticoids acting on the gut and kidney might cause increased mobilization of bone and overshadow any direct inhibitory effect of glucocorticoids. Such a direct inhibitory action of glucocorticoids on bone resorption may thus be unrecognized and only be detectable with small doses of the compound, larger quantities of glucocorticoids increasing bone resorption through the mechanism of a negative calcium balance.

If this negative calcium balance effect of glucocorticoids were corrected, the direct inhibitory effect of glucocorticoids on bone would predominate and oppose any effect of vitamin $\mathrm{D}$ in increasing bone resorption.

Bendrofluazide decreases urinary calcium and this may be accompanied by a slight rise in faecal calcium, calcium balance remaining unchanged (Nassim and Higgins, 1965).

The three drugs glucocorticoids, bendrofluazide and vitamin $\mathbf{D}$ can, therefore, oppose the individual actions of one another.

It has been shown that the negative calcium 
balance and hypercalciuria which occurs when glucocorticoids are administered can either be corrected (Cases 1 and 2) or prevented (Case 3) with vitamin D and bendrofluazide given together. Prednisolone would be expected to minimize any rise in plasma calcium due to vitamin $\mathrm{D}$ therapy, and bendrofluazide to reduce urinary calcium and prevent hypercalciuria. Administration of an adequate dose of vitamin $D$ is important; this is well demonstrated in Case 2 in whom $1 \mathrm{mg}$ of calciferol in combination with $5 \mathrm{mg}$ of bendrofluazide induced zero balance, whereas reduction of calciferol to $0.5 \mathrm{mg}$ /day caused a rise in faecal calcium which resulted in a negative calcium balance.

Thus by antagonizing the various actions of one another, vitamin D, bendrofluazide and glucocorticoids in combination can improve calcium balance with little risk of hypercalcaemia. On the other hand hypercalcaemia developed as calcium balance became more positive in patients not given glucocorticoids (Cases 4 and 5) and, as with intravenous calcium therapy, renal damage may occur (Bodfors, Lindahl and Lindahl, 1974).

Further studies are now required to assess whether correction of the hypercalciuria and negative calcium balance induced by glucocorticoids reverses or prevents the development of steroid-induced osteoporosis.

\section{Acknowledgments}

We would like to thank Professor P. G. Walker for his help and co-operation.

\section{References}

Bodfors, B., Lindahl, E. \& Lindahl, O. (1974) Optimum calcium therapy. Acta orthopaedica scandinavica, 45, 809.

Bunim, J.J., Black, R.L., Lutwak, L., Peterson, R.E. \& WhEDON, G.D. (1958) Studies on dexamethasone, a new synthetic steroid in rheumatoid arthritis - a preliminary report. Arthritis and Rheumatism, 1, 313.

Collins, E.J., Garrett, E.R. \& Johnston, R.L. (1962) Effect of adrenal steroid on radiocalcium metabolism in dogs. Metabolism, 11, 716.

Crawford, J.D., Gribetz, D., Diner, W.C., Hurst, P. \& Castleman, B. (1957) Influence of vitamin D on parathyroid activity and the metabolism of calcium and citrate during calcium deprivation. Endocrinology, 61, 59.

Dick, M. (1969) Use of cuprous thiocyanate as a short term continuous marker for faeces. Gut, 10, 408.

EISENBERG, E. (1966) Effects of androgens, estrogens and corticoids on strontium kinetics. Journal of Clinical Endocrinology and Metabolism, 26, 566.

Gallagher, J.C., Arron, J., Horsman, A., Wilkinson, R.
\& Nordin, B.E.C. (1973) Corticosteroid osteoporosis. Clinics in Endocrinology and Metabolism, 2, 355.

Geschwind, I. (1961) In: Mineral Metabolism: an Advanced Treatise (Ed. by Comar, C.L. \& Bronner, F.), Vol. 1, Part B, pp. 387-455. Academic Press, New York and London.

GraN, F.C. (1960) The retention of parenterally injected calcium in rachitic dogs. Acta physiologica scandinavica, 50, 132.

Harrison, M. \& Fraser, R. (1969) Bone structure and metabolism in calcium-deficient rats. Journal of Endocrinology, 21, 197.

JowSEy, J. \& GerShon-CoHEN, J. (1964) Effects of dietary calcium levels on production and reversal of experimental osteoporosis in cats. Proceedings of the Society for Experimental Biology and Medicine, 116, 437.

Jowsey, J., Kelly, P.J., Riggs, B.L., Bianco, A.J. Jr., Scholz, D.A. \& Gershon-Cohen, J. (1965) Quantitative microradiographic studies of normal and osteoporotic bone. Journal of Bone and Joint Surgery, 47A, 785.

MYERS, W.P.L. (1962) Studies of serum calcium regulations. Advances in Internal Medicine, 11, 163.

Nassim, J.R. \& Higgins, B.A. (1965) Control of idiopathic hypercalciuria. British Medical Journal, 1, 675.

Nisbet, J. \& Nordin, B.E.C. (1969) In: Les Tissus Calcifiés (Ed. by Milhaud, G., Owen, M. \& Blackwood, H.J.J.), p. 233. Société d'édition d'enseignement supérieur, Paris.

Nordin, B.E.C. (1973) Metabolic Bone and Stone Disease, pp. 39-40, 163. Churchill Livingstone, Edinburgh and London.

Nordin, B.E.C., Young, M.M., OxBy, C. \& Bulusu, L. (1968) Calculation of calcium absorption rate from plasma radioactivity. Clinical Science, 35, 177.

PAK, C.Y.C. \& BARTTER, F. (1972) Treatment of osteoporosiळ with calcium infusions. Seminars in Drug Treatment, 2, 39

Pechet, M.M., Bowers, B. \& Bartter, F.C. (1959) Metas bolic studies with a new series of 14 Diene steroids. It effects in normal subjects of prednisone, prednisolone, $9 \propto-$ fluoroprednisolone. Journal of Clinical Investigation, 38, 691.

Raisz, L.G., Trummel, C.L., Wener, J.A. \& Simmons, H. (1972) Effects of glucocorticoids on bone resorption. Endocrinology, 90, 961.

Riggs, B.D., Jowsey, J. \& Kelly, P.J. (1966) Quantitative microradiographic study of bone remodeling in Cushing's syndrome. Metabolism, 15, 773.

Slater, J.D.H., Heffron, P.F., Vernet, A. \& Nabarro, J.D.N. (1959) Clinical and metabolic effects of dexamethasone. Lancet, i, 173.

Stoerk, H.C. \& ARISON, R.N. (1961) Parathyroid activity in hydrocortisone injected rats. In: Inflammation and Diseases of Connective Tissue. Hahnemann Symposium (Ed. by Mills, L.C. \& Moyer, J.H.), p. 399. Philadelphia.

VERNer, J.V., ENGel, F.L. \& MCPherson, H.T. (1958) Vitamin D intoxication report of two cases treated with cortisone. Annals of Internal Medicine, 48, 765.

Wajchenberg, B.L., Pereira, V.G., Kieffer, J. \& Ursic, S. (1969) Effect of dexamethasone on calcium metabolism and ${ }^{47} \mathrm{Ca}$ kinetics in normal subjects. Acta endocrinologica. Copenhagen, 61, 173.

WAlKer, P.G. \& Collins, J.A. (1965) In: Bones Metabolism in Relation to Clinical Medicine (Ed. by Sissons, H.A.), p. 55. Pitman Medical Publishing Co., London. 